\title{
Health promoting green spaces Exploring pathways for mapping and analysis in Flanders (Belgium)
}

\author{
Peter VERVOORT, University of Antwerp // Government of Flanders, Belgium
} Ann PISMAN, Ghent University // Government of Flanders, Belgium

\begin{abstract}
Flanders (Belgium) is an urbanised region characterised by urban sprawl. Recently private green space in Flanders has been mapped (Somers, Van Valckenborgh, \& Strosse, 2020), complementing existing datasets and knowledge on green space. A growing scientific evidence supports positive effects of these green spaces on health outcomes. Research indicates associations with a lower mortality and morbidity (Kondo, Fluehr, McKeon, \& Branas, 2018). Evidence also suggests green space availability is related to improved physical and mental health (Bowler, Buyung-Ali, Knight, \& Pullin, 2010; Lee \& Maheswaran, 2010). However (public) green space is scarce, especially in sprawled environments. In line with the European policy intention to avoid additional land take, further densification is to be expected. This could result in diminishing the supply of green spaces while at the same time increasing the demand due to the increase in population. Our research aims to produce evidence on spatial differentiation of health promoting green space, suitable for actionable spatial planning in a context of densification. Green space is approached and studied from very different angles and perspectives, resulting in a wide range of methods for mapping and analysis. Drawing from a critical review of methods and practices, confronted with evidence on linkages between green space and health, an analytical framework is established and two new indicators are developed.

The results provide insights on mapping and analysing the spatial distribution of green space from a health promotion perspective in a Western European setting as a stepping stone for context specific research and spatial policy.
\end{abstract}

\section{Keywords}

Green Space, Health, Indicators, Mapping, Analysis 


\section{Introduction}

\subsection{Green space, health and equality}

The positive effects of green space on physical, mental and social health cannnot be overestimated. Researchers link the presence of green space to a reduction in cardiovascular disease, a superior cognitive and neurological development in children, a better mental health, an improved wellbeing and a good physical condition. (Kondo, Fluehr, McKeon, \& Branas, 2018; Lee \& Maheswaran, 2010; Maas, Verheij, Groenewegen, de Vries, \& Spreeuwenberg, 2006) However also negative effects of nearby green space, like increased risks of allergies and asthma, a greater chance of exposure to pesticides or herbicides, or to vector-borne diseases exist. Some green spaces are linked to increased criminality rates or to feelings of unsafety. (WHO Regional Office for Europe, 2016)

The explanation as to why greenery promotes health is not so obvious. Researchers consider a complex interplay of various underlying mechanisms responsible: contact with nature provides stimuli in the nervous system that make it easier to relax; green space is believed to play a role in the social cohesion and the establishment of social relationships; contact with nature and exposure to micro-organisms can improve immune system functioning; there are indications that green space encourages walking or physical exercising; natural sounds can mask environmental noise reducing people's discomfort; trees can reduce exposure to air pollution and heat; green space encourages people to spend more time outdoors, increasing exposure to sunlight - positively impacting sleep patterns and increasing levels of vitamin D. (WHO Regional Office for Europe, 2016)

Ensuring sufficient green space in the vicinity for everyone is an therefore an effective way to contribute to health prevention. A good understanding of the distribution of green space and of the inequalities citizens encounter to benefit from the available greenery is needed. The highest health gains can be reached when focusing on improving green space availability for vulnerable groups, minorities or people of lower socio-economic status, which generally live at locations with poorer environmental quality (Morello-Frosch, Zuk, Jerett, Shamasunder, \& Kyle, 2011) and face greater health risks, because they lack resources for a healthy diet, delay doctor's visits, are poorly housed or have less access to sports facilities (Feinstein, 1993).

\subsection{Policy Context}

Avoiding additional land take is high on the policy agenda. Europe targets no net additional land take by 2050 (Europese Commissie, 2011), Flanders wants to establish this already in 2040 (Vlaamse Regering, 2018). Reducing the increase in land take and the associated degree of paving is linked to the efficient use of natural resources and reduction of pressures on the ecosystem. To accomplish this, additional demands for land as a result of demographic changes (growth, dilution, etc.) will have to be accommodated at locations within the urban fabric.

Combining the two objectives of compacting and protecting green space is a challenge in Flanders, being a highly urbanised region characterised by urban sprawl: a conglomeration of relatively small urban centers and villages, within a patchwork of scattered built-up areas, gardens, fragments of nature, forest or agricultural areas (Pisman, Mertens, Loris, \& Vervoort, 2019; Vermeiren et al., 2019). Flanders, along with Malta, has the highest sprawl score in Europe (European Environment Agency and Federal Office for the Environment, 2016), moreover it has relatively few large nature reserves and forests since approximately one-third of the area is occupied by land take. 
The built-up area is spread over more than 1500 villages and cities, and more than $13,000 \mathrm{~km}$ of ribbon development (Pisman A., 2018).

(Part of) the private sector is joining in this densification effort. Under the influence of real estate logic, older industrial sites and green areas are increasingly making way for more profitable alternatives such as apartments (Pisman A., 2018). Recent analyses (to be published in late 2021) show that in Flanders some densification has taken place within the land take over the past 6 years, but green space has been lost in the process. Too often private gardens, vacant land or soccer fields are occupied, resulting in a net loss of (public and private) green space.

\subsection{Research focus}

To support a spatial policy aimed at ensuring health-promoting green space in a context of urban densification, the research has a twofold objective: To develop indicators (1) for analysis, monitoring and evaluation green space distribution in Flanders (macro-level), future forecasts and scenario analyses; (2) allowing to identify concrete areas for action (meso/micro-level) and ex-ante evaluation of interventions, projects and plans. This evidence will support (1) the development of a differentiated, generic regional policy, to monitor and evaluate the intended policy effects and (2) establishing context-specific policies and guiding concrete (spatial) interventions.

These research questions are addressed: How is 'green space in relation to residents' health' approached and operationalised within spatial analysis and policy? How can the supply of green space be assessed from the perspective of residents' health and that of the planning authorities? What types of green spaces are considered? How can green space availability be mapped for the entire territory of Flanders? How can this be used for policy on densification and green space distribution and guide concrete (spatial) interventions?

\section{Methodology}

This research explores how green space is approached and operationalised for analysis and assessment within the spatial discipline. Articles are selected from three scientific databases (The Lens, Web of Science, Scopus) using extended Boolean syntax. The search selects articles simultaneously containing words from the category "green space", "spatial planning" and "standards, analysis, frameworks", but no specific thematic words such as "temperature" or "physical activity". The aim is to find general methods for analysing or evaluating green space in the spatial discipline, without focusing too much on specific thematic analyses such as the effects of vegetation on ambient temperature. It is not the intention to create an exhaustive overview, but rather to summarise the main lines of current approaches and build on them. The search results are sorted according to 'relevance' (using the algorithms of the respective databases), the first 50 articles from each database are selected and screened for content. In the end, 77 unique articles are selected for substantive analysis. References and primary sources are considered when useful. The literature is complimented by known relevant sources. The insights are linked to evidence and literature on green space availability and health outcomes. A theoretical framework for analysis of green space is built up, and pathways to develop concrete indicators to analyse health promoting green space in a context of densification are laid out. 


\section{Urban green space and health in literature}

The term "green space" is interpreted very broadly. In literature, various definitions or descriptions are found, often these are rather vague or the meaning is even left implicit. In other words, there is no clear picture of what should be understood as green space. In an extensive study on green space typologies in Europe, researchers (Braquinho et al., 2015) derived 8 larger categories: building green; private, commercial, industrial and institutional green \& green linked to grey infrastructure; green on river banks; parks and recreation; allotments and community gardens; agricultural land; natural, semi-natural and wild areas; blue infrastructure. The World Health Organisation (WHO Regional Office for Europe, 2017) defines green space in the built environment as that space covered by vegetation, including: smaller green elements such as street trees and verges, green spaces that are not (publicly) accessible such as green roofs or facades and private green space, and larger contiguous green areas that perform different recreational and social functions such as parks, playgrounds or green links for slow traffic. It further emphasises larger green space structures such as urban forests have a regional scope and provide ecological, social and recreational services to different communities at a higher scale.

In general two major directions of interpretation can be distinguished (Taylor \& Hochuli, 2017). The first refers to a dichotomy whereby green space concerns natural, undeveloped areas, which contrasts with non-natural, built or paved areas. The second explicitly situates the concept of green space within the built (urbanised) context and is linked to the human experience of the green space. Non-natural elements (paths, terraces, benches, fences, squares, streets) can be part of, or determine, the green space, if they are important for the use or user experience. These green spaces are coherent spatial entities with a green character. This kind of green space cannot simply be mapped based on its physical characteristics, since it acquires significance through human experience. Both interpretations are used at different scales and levels of abstraction. The cited examples of green typologies or descriptions of green space (Braquinho et al., 2015; WHO Regional Office for Europe, 2017) show that both interpretations are also used simultaneously.

Most of the articles in the dataset focus on green space because they provide a wide range of ecosystem services (benefits to people) (e.g. Tzoulas et al. (2007), Baycan Levent and Nijkamp (2004), Kabisch and Haase (2014)). In the built context, mainly regulating and supporting services such as improving air quality, proving space for water retention or mitigating heat, and cultural ecosystem services, often linked to physical and mental health, are mentioned.

In the introduction possible pathways or mechanisms linking contact with nature to health effects are introduced. To promote health, green spaces in the built environment must therefore have various qualities: offer opportunities for rest and relaxation, children's play, physical exercise, contact or involvement with nature or mitigate noise, heat or crowding. A review (WHO Regional Office for Europe, 2016) indicates four global relevant characteristics: (1) the perception, proximity, accessibility and quality of green space; (2) the size of green space; (3) the facilities for specific activities within green space; (4) green impression, the proportion of green area, trees in particular. The perception, proximity and quality (attractiveness, safety, cleanliness, etc.) of green spaces are linked to more physical. The size of the green spaces affects the possibilities for use or certain activities. The attractiveness of a green space is also linked to amenities such as paths, benches, play elements, sports facilities, picnic areas or parking facilities. Finally, the general green impression of a neighbourhood is important. Visibility of green, and especially high green (trees), contribute to mental health and the reduction of stress.

A green space can however not continue to provide health promoting ecosystem services indefinitely with increasing demand (e.g. higher urban densities), due to overuse and overcrowding (Villamagna, Angermeier, \& Bennett, 2013). Crowded places can be stressful or create friction because not all people visit the green space for the same reason. Some may want peace and quiet, others want to hang out with friends. Moreover, there will literally be less space available, for example for sport or play, when more 
people have to use a specific green space. Therefore mapping health promoting green space should also address the demand for green space.

\section{Green space indicators}

Both accessible coherent green spaces (gardens, parks, recreational areas, etc.), linked to the use, and the share and type of vegetation in the environment (grass, flowers, bushes, trees), linked to the view of greenery, add to health promotion. Parameters used to measure the general supply of green space are mostly related to (1) location, distribution and accessibility (2) the quantity of green space in terms of area or ratio to the total area.

A commonly used method to identify the location of greenery is based on remote sensing data (aerial photos or satellite images), often through analysis of the NDVI index indicating the presence and nature of vegetation based on the reflected light spectrum (e.g. Vigneshwaran and Vasantha Kumar (2019)). This results, for example, in mappings that distinguish between paved and unpaved areas, the variety of crops or high green (trees) and low green (grass and bushes). To determine the location and accessibility of coherent spaces with a green character, mainly data from (local) governments are used. For instance inventories of the patrimony of public parks, cemeteries, forests, allotments, recreational areas, etc. (e.g. Kabisch and Haase (2014), J. Zhang et al. (2020)), a selection of certain categories within available land-use maps, mostly parks and recreational land use, (e.g. Zhu, Lang, Tao, Feng, and Liu (2019), Martins and Pereira (2018) sometimes also agricultural areas (e.g. Contesse, van Vliet, and Lenhart (2018)), are used. Features like the presence of specific vegetation or amenities such as benches or paths are mentioned to characterise or analyse green spaces. To a lesser extent, researchers combine these data with results from a participatory GIS exercise, in which residents are asked to indicate what they consider to be (accessible) green spaces (e.g. Luz et al. (2019)). Some articles opt for a sole interpretation - either greenery or coherent green spaces. However, both often occur together, or the data on greenery is a basis for identifying or characterising coherent green spaces (e.g. using remote sensing data to delineate private gardens (Haase, Janicke, \& Wellmann, 2019)).

Demand is mostly operationalised from a resident perspective (i.e. supply of green space in the immediate vicinity of the dwelling or in the neighbourhood), however sometimes all visitors are considered (e.g. Ćwik, Kasprzyk, Wójcik, Borycka, and Cariñanos (2018)). Linking supply of green space to demand, indicators include (1) the presence of (accessible) green space at specific distances from the dwelling and (2) the available surface area of (accessible) green space per individual resident or per capita or (3) a combination of both.

Analysis is done for a specific area, mostly at a neighbourhood or municipality level (e.g. neighbourhood capita per green area in Kabisch and Haase (2014)) or a regional level (e.g. differences in supply in different provinces in Zhang, Zeng, Zhang, Song, and Li (2020) or from the perspective of a distinct green area ( e.g. amount of visitors living at different distances of a park in Kabisch and Haase (2014)). Separate indicators can be mapped and analysed, some researchers combine a number of dimensions into one score (e.g. Building Neighbourhood Green Index combining the ratio of green space area, green space density, distance to dwellings and the urban density (Zhu et al., 2019)). This results in a global overview and allows easy comparison, but aggregation inevitably means loss of information.

\section{Green standards}

Various green space standards are mentioned in the literature, mostly indicating a minimum area of green space per capita. These 'standards' are mainly cited to demonstrate the supply of green space is insufficient or scarce (e.g. Bardham, Debnath, and Bandopadhyay (2016); Contesse et al. (2018)) or used as a benchmark to point out inequalities (e.g. Contesse et al. (2018). 
Particularly in Anglo-Saxon countries, the use of green standards by spatial planners is well established, presumably because of their simplicity and ease of use (Byrne, 2011). However, research (Wilkinson, 1985) has shown most standards lack a scientific basis, have never been empirically validated and have often been blindly copied. The origin or the rationale behind them is often unclear or not traceable. This also applies to the standards mentioned in the articles in the dataset. The most frequently cited standard, a minimum of $9 \mathrm{~m}^{2}$ green space per person, which is supposedly recommended by the World Health Organisation, is not at all mentioned in the cited document (WHO, 2012). Although the evidence base of many green standards is unclear, they do address the issue of balancing urban density and liveability.

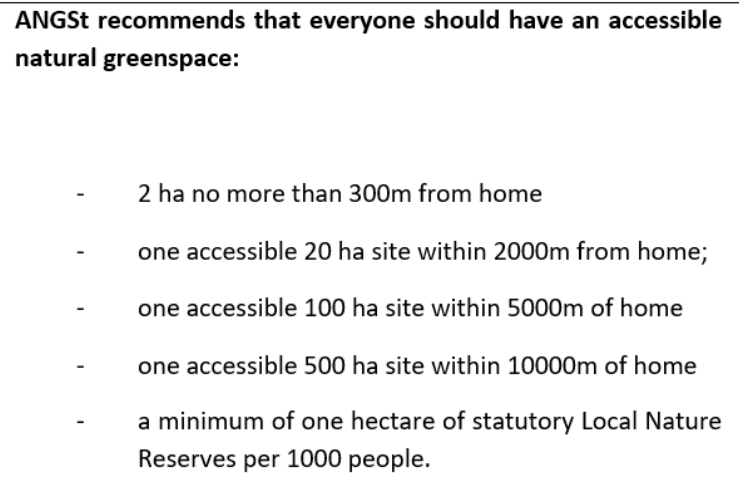

\begin{tabular}{|c|c|c|}
\hline $\begin{array}{l}\text { Functional level } \\
\text { Greenspace Flanders }\end{array}$ & $\begin{array}{l}\text { Maximum } \\
\text { distance }\end{array}$ & $\begin{array}{l}\text { Minimal } \\
\text { area }\end{array}$ \\
\hline Residential green & $150 \mathrm{~m}$ & / \\
\hline Neighbourhood green & $400 \mathrm{~m}$ & 0,2 ha \\
\hline Community green & $800 \mathrm{~m}$ & 10 ha \\
\hline District green & $1600 \mathrm{~m}$ & 30 ha \\
\hline City Green & $3200 \mathrm{~m}$ & 60 ha \\
\hline City forest & $5000 \mathrm{~m}$ & 200 ha \\
\hline
\end{tabular}

Table 1: left: Accessible Natural Greenspace Standard (UK), right: Flanders green space supply monitoring indicators (B)

An often cited green space standard is the Accessible Natural Greenspace Standard (Natural England, 2010) from the United Kingdom that specifies minimum areas of accessible green space within certain perimeters of the dwellings and a minimum area of nature reserve per resident. In Flanders, there are no official regional standards, but the supply of accessible green space is monitored in a similar way (Strosse, Salomez, Hermy, \& Pisman, 2018).

\section{Theoretical framework}

From the health perspective of the user (often the resident), two aspects are paramount: (1) the provision of accessible green space in the vicinity of the dwelling, linked to number of users; (2) the presence of a views of greenery (especially high vegetation and trees) both from the dwelling itself, and in the wider surroundings.

The spatial professional translates the user perspective into the provision of private and public green space (for example, imposed in zoning plans or permits), regulating (garden) vegetation or developing and maintaining a greener public domain. In addition, other spatial aspects such as building typologies or maximum dwelling densities, which influence both supply and demand, can be accounted for. 


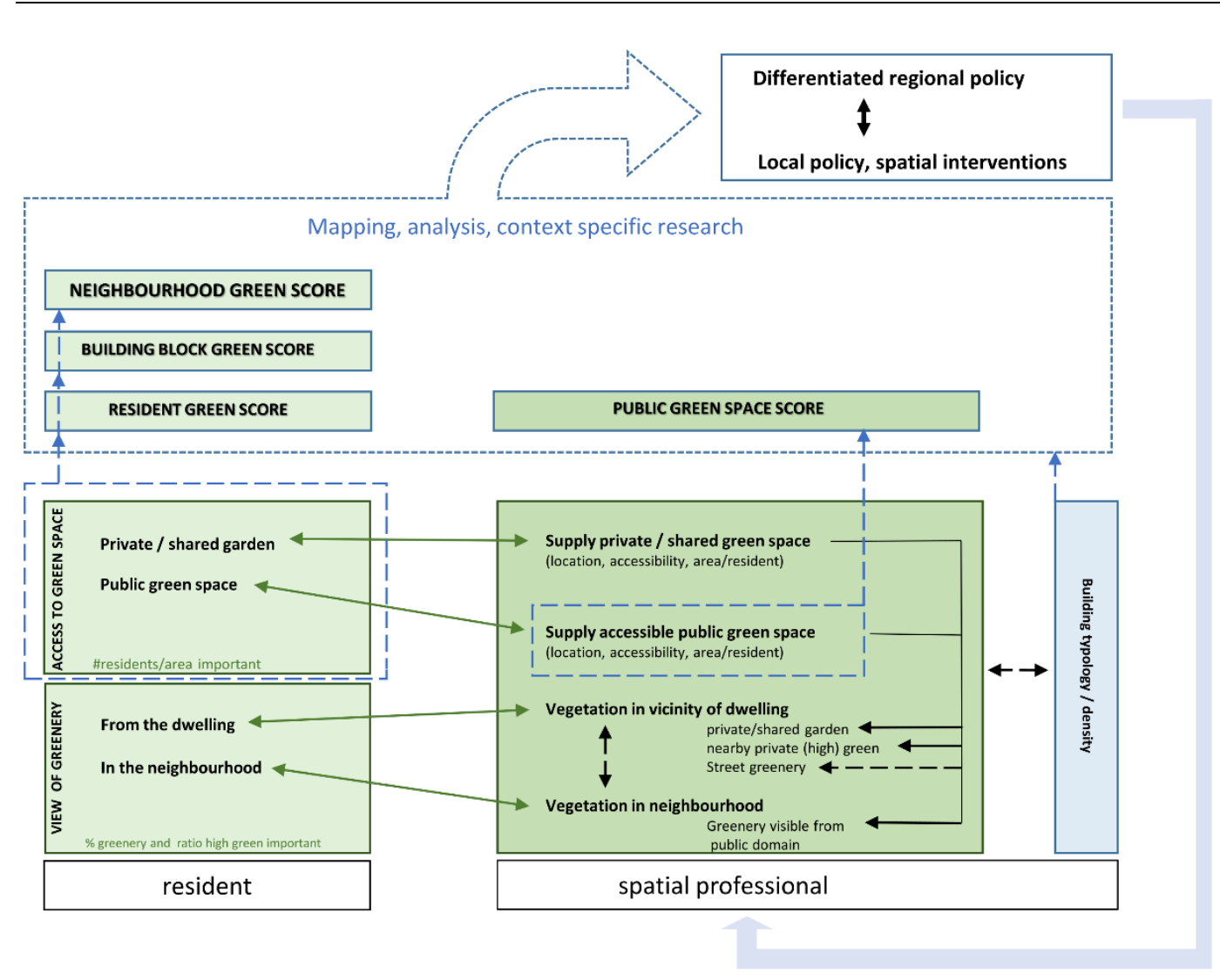

Figure 1: Theoretical framework green space and health

Both perspectives are important for regional spatial policy or local policy and concrete interventions.

Indicators drawn from the user's perspective allow to study the variation in access to green space or views on green space within the population. These green scores can be aggregated at various scales (e.g. individual resident, building, block, neighbourhood) and linked to spatial (e.g. building typology, morphological characteristics or degree of urbanisation), demographic (e.g. ratio children or elderly) or socio-economic (e.g. income or poverty) parameters. They can reveal specific problems or directions for action (both generic or at specific locations). Indicators constructed from the point of view of green space (e.g. public green space scores) provide complementary insights. These indicators give an insight into the differentiation in the balance between supply and demand of the green spaces itself. They can indicate green spaces with high demand and show effects of additional densification on these green spaces.

\section{Results}

This article will focus on the development of indicators concerning accessible green spaces (gardens, parks, recreational areas, etc.), however it should be noted that complementary indicators on greenery and trees in the vicinity could and should be elaborated in a later stage as well. Since the green space supply monitoring indicators in Flanders (table 1) are well known and used within the spatial planning community, they provide a good basis for developing indicators. Accessible green spaces are identified by combining data on private gardens (GARMON, 2020), and data on accessible green space (i.e. green space that can be reached from the public domain) (Agentschap Binnenlands Bestuur, 2018). Data on residents at address level provide information on the location and number of potential users. 


\subsection{Green scores from a resident perspective}

The green score measures the supply of available green space per resident at address level. The indicator takes into account the surface area of the green space and the number residents in the vicinity. The indicator is composed of the supply of private green space and various categories of public green space per resident.

First, the surface area of the private or shared garden is calculated and divided by the total number of residents at the parcel. Next, for every address the number of residents (Greek letters in figure 2) is distributed evenly over the area of different categories of public green space within the corresponding distance buffers (Roman letters in figure 2). This results in a dataset showing a differentiation of distributed number of residents within every green area for each of the categories of public green space. To conclude for every resident the total amount of green area per category is divided by the total number of residents distributed to these green areas. This results in a total area per resident per category of green space.

resident green score $=$

$\frac{\text { area private green space }}{\# \text { residents }}+a *\left(\frac{\text { area neighbourhood green space }}{\# \text { residents }}\right)+b *\left(\frac{\text { area community green space }}{\# \text { residents }}\right)+c *\left(\frac{\text { area district green space }}{\# \text { residents }}\right)$

More research has to be carried out to determine the weights given to every category, however assumedly these weights will diminish with the distance from the dwelling. Making use of the available geo-data on building blocks and neighbourhoods (census boundaries) the scores can be aggregated at larger scales. The different levels of scores from a resident perspective can be crossed with spatial (morphological or functional), demographic and socio-economic data for further analysis.
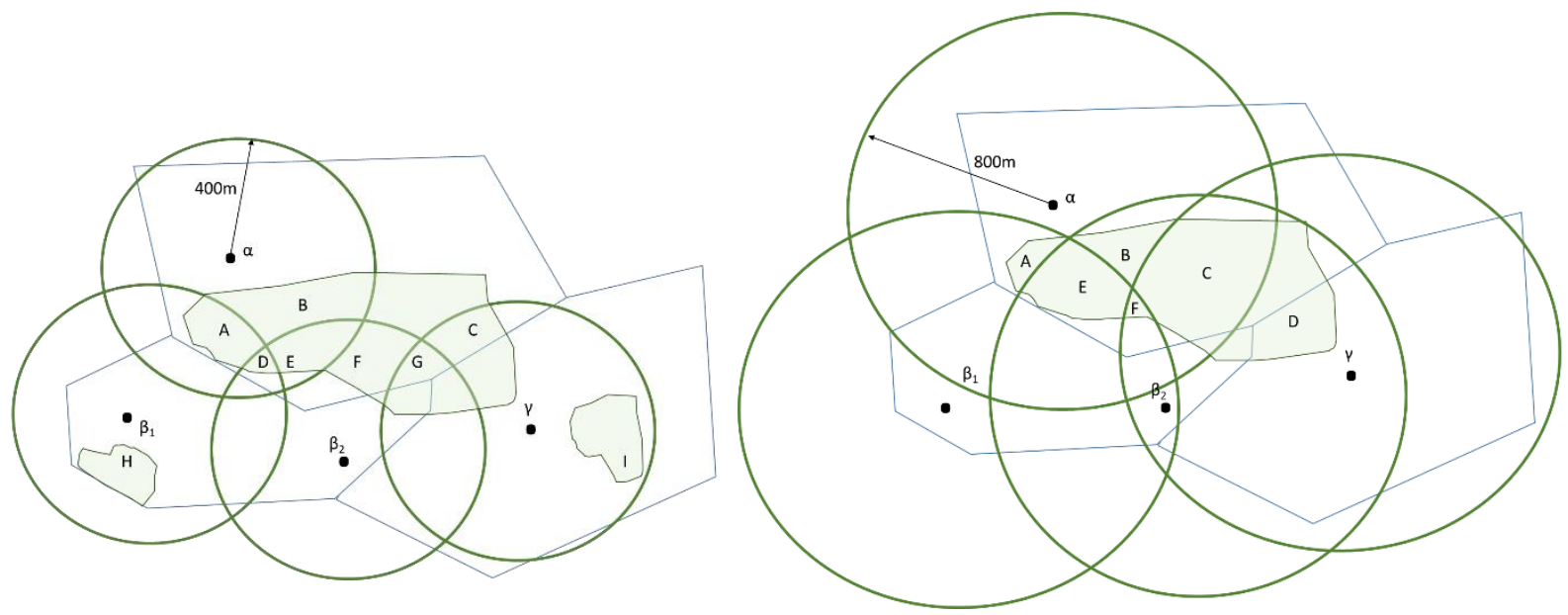

Figure 2: Calculating principle. Left: neighbourhood green (minimal area 0,2 ha, distance $400 \mathrm{~m}$ ), Right: community green (minimal area $10 \mathrm{ha}$, distance $800 \mathrm{~m}$ )

\subsection{Green scores from the perspective of public green spaces}

A green score per public green space cluster can be calculated by taking in to account the total number of residents using it as neighbourhood green, community green, district green, etc.. For instance (Figure 3) for very small green spaces $(0,2-10 \mathrm{ha})$ the surface area is divided by the amount of residents (Greek letters) 
in a Euclid buffer of $400 \mathrm{~m}$. For small green spaces (10-30 ha) also the residents within a Euclid buffer of $800 \mathrm{~m}$ are taken into account. This results in:

Public green score small green spaces $(10-30 \mathrm{ha})=$

$$
\frac{\text { area public green space }}{\text { \#residents within } 400 \mathrm{~m}}+a *\left(\frac{\text { area public green space }}{\# \text { residents within } 800 \mathrm{~m}}\right)
$$

Again, more research has to be carried out to determine the weights given to every category.
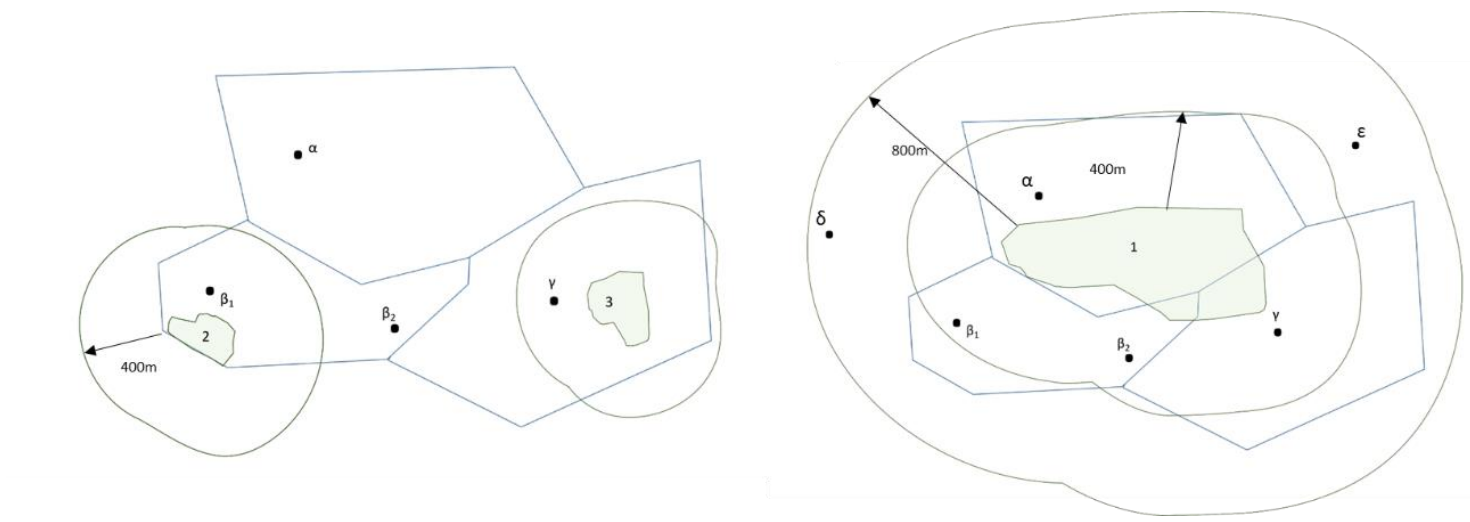

Figure 3: Calculating principle. Left: very small green space $(0,2$ ha-10ha, distance $400 \mathrm{~m})$, Right: small green space (10 ha - 30ha, distances 400 and $800 \mathrm{~m}$ )

\section{Conclusion and discussion}

The assessment of the spatial distribution of health promoting green space requires indicators that give insights in the balance between supply and demand. Based on existing monitoring standards and available datasets for the entire territory of Flanders our methodology produces indicators from the perspective of (1) the user (resident) and (2) the green space clusters. This dual approach results in indicators linked (1) to the resident and their living environment (dwelling, building block, neighbourhood) which can be crossed with spatial, demographic or socio-economic parameters and (2) to the distinct green spaces which can be analysed in relation to the surrounding urban fabric and population densities.

These indicators enable global understanding and provide a starting point for indepth research. However because of the aspiration to establish a territory wide set of indicators they operate at a rather abstract level, based on features as surface area, theoretical distances, population density and land use data and assuming an equally visits to all available green space clusters. As mentioned other aspects are important to consider: for instance quality, diversity in green space types, provision of amenities, aspects of perception, experience, safety or nuisance. Also differences in human behaviour and preferences or differences between age groups, people with different socio-economic or cultural backgrounds or people with disabilities should be taken into account. Addressing mostly aspects of equity in distribution, also enabling participation in the processes of enhancing environmental conditions is needed to ensure sustainable health benefits for the most vulnerable. Nevertheless, the proposed indicators provide a sound basis for a context specific assessment, including resident participation, identifying specific needs or required levels of green space provision. 


\section{References}

Agentschap Binnenlands Bestuur. (2018). Gemeente-en stadsmonitor Vlaanderen.

Bardham, R., Debnath, R., \& Bandopadhyay, S. (2016). A conceptual model for identifying the risk susceptibility of urban green spaces using geo-spatial techniques. Modeming earth systems and environment, 2(144), 12.

Baycan Levent, T., \& Nijkamp, P. (2004). Urban Green Space Policies: Performance and Success Conditions in European Cities. Paper presented at the 44th European Congress of the European Regional Science Association, Porto, Portugal.

Braquinho, C., Cvejić, R., Eler, K., Gonzales, P., Haase, D., Hansen, R., . . Železnikar, Š. (2015). A typology of urban green spaces, ecostem provisioning services and demands. GREEN SURGE deliverable 3.1.

Byrne, J. (2011). Greenspace Planning: Problems with Standards, Lessons form Research, and Best Practices. CITYGREEN Nature and Health in Cities, 1(6).

Contesse, M., van Vliet, B. J. M., \& Lenhart, J. (2018). Is urban agriculture urban green space? A comparison of policy arrangements for urban green space and urban agriculture in Santiago de Chile. Land Use Policy, 71, 566-577.

Ćwik, A., Kasprzyk, I., Wójcik, T., Borycka, K., \& Cariñanos, P. (2018). Attractiveness of urban parks for visitors versus their potential allergenic hazard: A case study in Rzeszów, Poland. Urban forestry \& Urban Greening, 35, 221-229.

European Environment Agency and Federal Office for the Environment. (2016). Urban sprawl in Europe. joint EEA-FOEN report. Luxemburg: Publications Office for the European Union.

$\operatorname{COM(2011)~} 571$ - Stappenplan voor efficiënt hulpbronnengebruik in Europa, (2011).

Feinstein, J. S. (1993). The relationship between socioeconomic status and health: a review of the literature. The Milbank Quarterly, 71(2), 279-322.

GARMON. (2020). The Garden Monitor - mapping and characterizing gardens using remote sensing.

Haase, D., Janicke, C., \& Wellmann, T. (2019). Front and back yard green analysis with subpixel vegetation fractions from earth observation data in a city. Landscape and Urban Planning, 182, 44-54.

Kabisch, N., \& Haase, D. (2014). Green justice or just green? Provision of urban green spaces in Berlin, Germany. Landscape and Urban Planning, 122(129-139).

Kondo, M., Fluehr, J., McKeon, T., \& Branas, C. (2018). Urban green space and its impact on human health. International Journal of Environmental Research and Public Health, 15(3). doi:10.3390/ijerph15030445

Lee, A., \& Maheswaran, R. (2010). The health benefits of urban green spaces: a review of the evidence. Journal of Public Health, 54(3), 6.

Luz, A. C., Buijs, M., Aleixo, C., Metelo, I., Grilo, F., Branquinho, C., . . Pinho, P. (2019). Should I stay or should I go? Modelling the fluxes of urban residents to visit green spaces. Urban forestry \& Urban Greening, 40, 195-203.

Maas, J., Verheij, R. A., Groenewegen, P. P., de Vries, S., \& Spreeuwenberg, P. (2006). Green space, urbanity, and health: how strong is the relation? Journal of Epidemiology and Community Health, 60(7), 587-592.

Martins, B., \& Pereira, A. N. (2018). Index for evaluation of public parks and gardens proximity based on the mobility network: A case study of Braga, Braganza and Viana do Castelo (Portugal) and Lugo and Pontevedra (Spain). Urban Forestry and Urban Greening.

Morello-Frosch, R., Zuk, M., Jerett, M., Shamasunder, B., \& Kyle, A. D. (2011). Understanding the cumulative impacts of inequalities in environmental health: implications for policy. Health Affairs, 30(5).

Natural England. (2010). 'Nature Nearby' Accessible Natural Greenspace Guidance. Retrieved from

Pisman, A., Mertens, G., Loris, I., \& Vervoort, P. (2019). Urban sprawl in Vlaanderen. Ruimtelijke en financiële winsten door het investeren in anti urban sprawl maatregelen. Paper presented at the Plandag 2019. Meer met meer., Turnhout.

Pisman A., V. S., Willems P., Engelen G. \& Poelmans L. (2018). Ruimterapport Vlaanderen (RURA). Een ruimtelijke analyse van Vlaanderen. Brussel: Departement Omgeving.

Strosse, V., Salomez, J., Hermy, J., \& Pisman, A. (2018). Ruimte voor open ruimte. In A. Pisman, S. Vanacker, P. Willems, Engelen G., \& L. Poelmans (Eds.), Ruimterapport Vlaanderen (RURA). Een ruimtelijke analyse van Vlaanderen. Brussel: Departement Omgeving.

Taylor, L., \& Hochuli, D. F. (2017). Defining greenspace: Multiple uses across multiple diciplines. Landscape and Urban Planning, 158, 25-38. 
Tzoulas, K., Korpela, K., Venn, S., Ylipelkonen, V., Kazmierczak, A., Niemela, J., \& James, P. (2007). Promoting Ecosystem and Human Health in Urban Areas using Green Infrastructure: A Literature review. Landscape and Urban Planning, 81, 167-178.

Vermeiren, K., Poelmans, L., Engelen, G., Broeckx, S., Beckx, C., De Nocker, L., \& Van Dyck, K. (2019). Monetariseren van de impact van urban sprawl in Vlaanderen, onderzoek uitgevoerd in opdracht van het Departement Omgeving.

Vigneshwaran, S., \& Vasantha Kumar, S. (2019). Comparison of classification methods for urban green space extraction using very high resolution worldview-3 imagery. Geocarto International.

Villamagna, A. M., Angermeier, P. L., \& Bennett, E. M. (2013). Capacity, pressure, demand and flow: a conceptual framework for analysing ecosystem provision and delivery. Ecological Complexity, 15, 114-121.

Vlaamse Regering. (2018). Strategische visie van het BRV. Brussel: Vlaamse Regering

WHO. (2012). Health Indicators of sustaiable cities. Paper presented the United Nations Conference on Sustainable Development, Rio de Janeiro, Brazil, 20-22 June 2012.

WHO Regional Office for Europe. (2016). Urban green spaces and health. Copenhagen.

WHO Regional Office for Europe. (2017). Urban Green Space Interventions and Health: A review of impacts and effectiveness. Retrieved from Copenhagen:

Wilkinson, P. F. (1985). The golden fleece: the search for standards. Leisure Studies, 4(2), 189-2003.

Zhang, J., Yu, Z., Cheng, Y., Chen, C., Wan, Y., Zhao, B., \& Vejre, H. (2020). Evaluating the disparities in urban green space provision in communities with diverse built environments: The case of a rapidly urbanizing Chinese city. Building and Environment, 183(107170).

Zhang, T., Zeng, Y., Zhang, Y., Song, Y., \& Li, H. (2020). Dynamic and Heterogeneous Demand for Urban Green Space by Urban Residents: Evidence from the Cities in China. Sustainability, 12(9384).

Zhu, Z., Lang, W., Tao, X., Feng, J., \& Liu, K. (2019). Exploring the Quality of Urban Green Spaces Based on Urban Neighborhood Green Index-A Case Study of Guangzhou City. Sustainability, October 